\title{
Meditation as an Alternative State of Consciousness
}

\author{
Dr. Bani Narula ${ }^{1} *$
}

\section{ABSTRACT}

This paper provides an analysis of meditation as a new way of managing stress, tension and crisis. Contemporary psychology of mediation has gained worldwide significance and acceptance to seek solace and solutions for modern problems. Originally mediation was meant to help deepen understanding of the mystical and sacred forces of life. But, these days, it is commonly used for relaxation and stress reduction. Meditation is a practice of concentrated focus upon a sound, object, visualization or attention itself in order to increase awareness of the present moment and enhance personal and spiritual growth. It is an altered state of consciousness or altered state of mind, which is a temporary change in one's normal mental state without being considered unconscious. Meditation provides a way for personal empowerment to become more in control of one's thinking, emotions and behaviour. Therefore, as per the perspective of modern psychology, meditative practices hold utmost significance in augmenting the understanding of mind-body relationship.

Keywords: Meditation, Consciousness

Today's era is witnessed as an overall improvement in one's lifestyle in terms of material comforts, new technology and globalisation. However, at the same time such advancement and developments have not only changed the traditional values and ethics but also has engulfed people of this competitive world where self image, looking after one's own interests and avoiding being a loser are important values. Thus, the emerging scenario is heading towards stress, conflict and tension. Hence the solutions to our modern difficulties is not about altering our external conditions rather bringing a change internally in one's thought pattern, mindset and perspective (Sood, 2009).

The question of how to reduce negativity like stress, anxiety, self-criticism and cultivate peace, calmness and change in one's perspective has become a topic of growing scientific interest in this day and age and the route to minimize the above said issues is best understood with recent developments in the field of contemporary psychology of meditation. (Goyal, Singh, Sibinga, Gould, Rowland-Seymour, Sharma, Berger, Sleicher, Maron, Shihab, Ranasinghe, Linn, Saha,

\footnotetext{
${ }^{1}$ Assistant Professor, Department of Psychology, D.A.V College, Chandigarh

*Responding Author

(C) 2016 I B Narula; licensee IJIP. This is an Open Access Research distributed under the terms of the Creative Commons Attribution License (http://creativecommons.org/licenses/by/2.0), which permits unrestricted use, distribution, and reproduction in any Medium, provided the original work is properly cited.
} 
Bass, Haythornthwaite (2014). Therefore, in this context, from classical philosophers to ancient religions, all the way to the modern self-improvement industry - Meditation has been offered as a way of increasing our basic happiness and well-being (Lane et al, 2007).

The word meditation is derived from a Sanskrit word meaning both an act of inner contemplation and the state of consciousness that occurs between attending to something and being fully absorbed in it. As the Bhagavad Gita says "The man whose mind is not under his control has no self-knowledge and no contemplation either. Without contemplation he can have no peace; and without peace, how can he have happiness?” (Adiswarananda, 2006).

Mental health, once defined in terms of absence of illness, has gradually become understood in a more holistic way, which also includes the positive qualities that help people flourish. This evolving definition of mental health has led to an exploration of other traditions and practices, including meditation, which for thousands of years have been devoted to developing an expanded vision of human potential (Husain et al, 2010). The emergence of the study of consciousness in psychology reflects a change in the mentality of people. Today people are more troubled by existential problems than hysteric symptoms (Lee et al, 2007). People are asking questions about self-actualization and the possibility of growth instead of how to get rid of pathological symptoms. Consciousness is also becoming a new approach in psychology, a new way of looking at behavior, based on systems theory and the holistic method. An altered state of consciousness is a temporary change in one's normal mental state without being considered unconscious. Altered states of consciousness can be created intentionally, or they can happen by accident or due to illness.

\section{Definitions of Meditation}

According to Govinda, (1978), Meditation is defined as turning inward; quiet observation, reflection and awareness of ourselves; to be conscious of consciousness; to become a detached observer of the stream of changing thoughts, feelings, drives and visions, until their nature and origin are recognized. Ornstein (1972) referred meditation to a set of techniques, which are the products of a different type of psychology that aims at personal rather than intellectual knowledge. Recently, Walsh \& Shapiro (2006) defined meditation as a family of self-regulation practices that focus on training attention and awareness in order to bring mental processes under greater voluntary control and thereby foster general mental well-being and development and/or specific capacities such as calm, clarity, and concentration. Thus the basic understanding of meditation is to cultivate the practice of turning your attention to a single point of reference. It can involve focusing on the breath, on bodily sensations, or on a word or phrase known as a mantra. In other words, meditation means turning your attention away from distracting thoughts and focusing on the present moment. 


\section{Types of Meditation}

Broadly meditation falls in the following categories (Seaward, 2009). Firstly, Concentrative Meditation- which aim is to cultivate a single-pointed attention on some object, such as a sound or an image and through the training of consistently returning to the object of focus, the mind develops the capacity to remain calm, stabilized, and grounded. Many Western meditation trainers start beginners with this practice, most commonly focusing on the breath. In some advanced practices, states of bliss may be reached. The most well-known and researched form of the concentrative type in the West is Transcendental Meditation (TM). Secondly, Open Awareness- whose objective is to open the mind into a panoramic awareness of whatever is happening without a specific focus. Often this awareness is compared to the spacious sky or a river with objects floating by. The capacity to be present with whatever arises is developed through this practice. The Zen sitting practice zazen is an example of this form of meditation practiced in the West. Thirdly, is the most popular, widely adapted, and researched meditation technique in the West is known as Mindfulness meditation, which is a combination of concentration and open awareness. The practitioner focuses on an object, such as the breath, bodily sensations, thoughts, feelings, or sounds. The focus is not as narrow as in concentrative meditation, for there is a simultaneous awareness of other phenomena. This mindfulness practice is often extended to daily actions, such as eating, walking, driving, or housework. Fourthly, Guided Meditation i.e. meditation can be guided, and many are often practiced with recorded or in-person guidance at first, and then later with decreasing need for explicit guidance. In one form, called guided imagery, the practitioner follows auditory guidance from a teacher or recording that elicits certain images, affirmations, states (such as peacefulness), or imagined desired experiences. Guided imagery is popular in the West to facilitate health and well-being and is often used to rehearse successful outcomes of procedures, such as surgery or an athletic performance.

Other forms include Qi gong i.e. a meditative practice that generally combines meditation, relaxation, physical movement and breathing exercises to restore and maintain balance. Tai chi is another form of meditation, where one performs a self-paced series of postures or movements in a slow, graceful manner while practicing deep breathing. Transcendental meditation is a simple, natural technique where one silently repeats a personally assigned mantra, such as a word, sound or phrase, in a specific way. This form of meditation allows one's body to settle into a state of profound rest and relaxation and mind to achieve a state of inner peace, without needing to use concentration or effort. Lastly, Yoga where performs a series of postures and controlled breathing exercises to promote a more flexible body and a calm mind. As one moves through poses that require balance and concentration, we are encouraged to focus less on your busy day and more on the moment.

In today's times Informal methods of meditation are used quite frequently amongst all age groups and which include: 
- Warm bath, hot tub, and sauna.

- Rituals of various kinds having tea (green/herbal), chanting, singing, dancing, listening to music.

- Rocking back and forth in a rocking chair.

- Sitting on the seashore watching and listening to the waves coming in rhythmically.

\section{Elements of Meditation}

Different types of meditation may include different elements to help you meditate (Creagan, 2011). Some of the most common features in meditation include:

- Focused attention. Focusing your attention is what helps free your mind from the many distractions that cause stress and worry. You can focus your attention on such things as a specific object, an image, a mantra, or even your breathing.

- Relaxed breathing. This technique involves deep, even-paced breathing using the diaphragm muscle to expand your lungs. The purpose is to slow your breathing, take in more oxygen, and reduce the use of shoulder, neck and upper chest muscles while breathing so that you breathe more efficiently.

- A quiet setting. Practicing meditation may be easier if you're in a quiet spot with few distractions, including no television, radios or cellphones.

- A comfortable position. You can practice meditation whether you're sitting, lying down, walking, or in other positions or activities. Just try to be comfortable so that you can get the most out of your meditation.

Further, the sequence of meditation involves two steps i.e. relaxation or quieting the body and concentration or a focusing or opening of the body-mind and spirit. Once the physical body is quiet and our consciousness is focused, we can, move to the level of contemplation, where we sense a connection between us and what we are attentive to, or to unification in which we share an intimate relationship with the object of our attention Horowitz (2010).

\section{Benefits of Meditation}

Meditation basically helps in two ways i.e. firstly; it prevents stress from entering the system and secondly, simultaneously releases accumulated stress. (Benson, 1975; Lane et al, 2007).

- Reduces tension, anxiety, irritability, depression.

- Increases alertness, serenity, concentration (likely by getting us to optimum state of arousal).

- Increased creativity and productivity.

- Decreased blood pressure in hypertensives, reduce coronary risk.

- Decreased compulsive worrying, negative thoughts, self criticism.

- Strengthened sense of identity.

- Decreases addictive behaviour (for long term meditators).

- Anger and disappointments become fleeting emotions that occur momentarily and then vanish. 


\section{Applications of Meditation}

Meditation has varied applications, its scope ranging from simple relaxation to self-realization. According to Kumar, (2001) following are some important applications:

- Behavioural: Meditation leads to an enhancement of efficiency in terms of focal attention, present-centredness, skill in action, and decision making.

- Clinical: It includes heightening of awareness of physiological and psychological processes leading to their voluntary control and inducing psychobiological and psychotherapeutic effects due to meditation.

- Epistemological: Acquisition of knowledge of self and reality through a process of transcendence, in which meditation serves as "experiential way" as contrasted with "empirical way".

- Psychological: Meditation enables effecting changes in different aspects of mental functioning and personality, personal growth and self-actualization and inducing changes in interpersonal and social behaviour.

- Socio-cultural: Meditation aids at fostering a sense of belongingness and oneness of humanity and oneness with cosmos, through a shift in perspective.

In nutshell it can be said that meditation is a reliable way of reducing stress and improving one's physical and mental health. It provides a way to empower oneself to not only obtain serenity but also a greater sense of personal empowerment to which one befall more in control of one's thinking, emotions, and behaviour (Ospina et al, 2007).

\section{REFERENCES}

Adiswarananda, S. (2006) The Four Yogas : A guide to the spiritual paths of action, devotion, meditation and knowledge. New York: Ramakrishna-Vivekananda Center of New York ; Woodstock. Vt.: Skylight Paths Publishers. 1st Edition.

Benson H. (1975). The relaxation response. New York: Morrow.

Creagan, E.T. (2011). (Expert opinion). Mayo Clinic, Rochester, Minn. March 22, 2011.

Govinda, L.A. (1978). Creative meditation and multidimensional consciousness.

Goyal, M; Singh, S; Sibinga, E. M.; Gould, N. F.; Rowland-Seymour, A; Sharma, R; Berger, Z; Sleicher, D; Maron, D. D.; Shihab, H. M.; Ranasinghe, P. D.; Linn, S; Saha, S; Bass, E. B.; Haythornthwaite, J. A. (2014). "Meditation Programs for Psychological Stress and Well-being: A Systematic Review and Meta-analysis". JAMA Internal Medicine 174 (3), 357-68. doi:10.1001/jamainternmed.2013.13018.

Horowitz, S. (2010). Health benefits of meditation: What the newest research shows. Alternative and Complementary Therapies, 16, 223.

Hussain, D. et al. (2010). Psychology of meditation and health: Present status and future directions. International Journal of Psychology and Psychological Therapy, 10, 439.

Kumar, S.K.K. (2001). Contextual approach to meditation and Integral Psychology. In M. Cornellison (Ed.) Consciousness and its transformation- Papers presented at the Second 
International Conference of Psychology. Sri Aurobindo Ashram, Pondicherry: Sri Aurobindo International Centre for Education.

Lane, J.D. et al. (2007). Brief meditation training can improve perceived stress and negative mood. Alternative Therapies in Health and Medicine, 13:38.

Lee, S.H. et al. (2007). Effectiveness of a meditation-based stress management program as an adjunct to pharmacotherapy in patients with anxiety disorder. Journal of Psychosomatic Research, 62-189.

Ornstein, R. E. (1972). The psychology of consciousness. San Francisco: W. H. Freeman \& Co.

Ospina, M.B. et al. (2007). Meditation practices for health: State of the research. Agency for Healthcare Research and Quality. U.S. Department of Health and Human Services. http://www.ahrq.gov/downloads/pub/evidence/pdf/meditation/medit.pdf. Accessed March 21, 2011.

Seaward, B.L. (2009). Meditation. In Managing Stress: Principles and Strategies for Health and Well-Being. 6th ed. Sudbury, Mass.: Jones \& Bartlett Publishers, 352.

Sood, A. (2009). Train Your Brain, Engage Your Heart, Transform Your Life: A Course in Attention \& Interpretation Therapy (AIT). Morning Dew Publications.

Walsh, R. \& Shapiro, S.L. (2006). The Meeting of Meditative Disciplines and Western Psychology. A Mutually Enriching Dialogue. American Psychologist, 61, (3), 227-239 DOI: 10.1037/0003-066X.61.3.227 